\title{
BIOFUEL PRODUCTION OVER FISCHER-TROPSCH SYNTHESIS: EFFECT OF Fe-Co/meso-HZSM-5 CATALYST WEIGHT ON PRODUCT COMPOSITION AND PROCESS CONVERSION
}

\author{
Jimmy Jimmy $\square$ \\ Department of Chemical Engineering \\ National Institute of Technology (ITN Malang) \\ Jln. Bendungan Sigura-gura, Malang, East Java, Indonesia, 65145 \\ j_roring@yahoo.com \\ Achmad Roesyadi \\ Department of Chemical Engineering ${ }^{l}$ \\ Suprapto Suprapto \\ Department of Chemical Engineering ${ }^{1}$ \\ Firman Kurniawansyah \\ Department of Chemical Engineering ${ }^{1}$ \\ ${ }^{1}$ Institut Teknologi Sepuluh Nopember \\ ITS Sukolilo Campus, Surabaya, East Java, Indonesia 60111
}

$\bowtie$ Corresponding author

\begin{abstract}
Fischer-Tropsch Synthesis (FTS) using Fe-Co/meso-HZSM-5 catalyst has been investigated. The impregnated iron and cobalt on HZSM-5 could be used as bifunction catalyst which combined polimerizing synthesis gas and long hydrocarbon cracking for making biofuel (saturated $\mathrm{C}_{5}-\mathrm{C}_{25}$ hydrocarbons as gasoline, kerosene and diesel oil). The study emphasized the effect of catalyst weight on product composition and process conversion. The HZSM-5, had been converted from ammonium ZSM-5 through calcination, and then desilicated with $\mathrm{NaOH}$ solution. The $\mathrm{Co}\left(\mathrm{NO}_{3}\right)_{2} \cdot 6 \mathrm{H}_{2} \mathrm{O}$ and $\mathrm{Fe}\left(\mathrm{NO}_{3}\right)_{3} \cdot 9 \mathrm{H}_{2} \mathrm{O}$ were used as precursor for incipient wetness impregnation (IWI) on amorphous meso-HZSM-5. The catalyst consisted of $10 \%$ Fe and $90 \%$ Co by weight, called $10 \mathrm{Fe}-90 \mathrm{Co} / \mathrm{meso}-\mathrm{HZSM}-5$. All catalysts were reduced in situ in the continuous reactor with flowing hydrogen at $25 \mathrm{~mL} / \mathrm{min}$, 1 bar, $400{ }^{\circ} \mathrm{C}$ for 10 hours. The catalyst performance was observed in the same continuous fixed bed reactor at $25 \mathrm{~mL} / \mathrm{min} \mathrm{syn-}$ thesis gas $\left(30 \% \mathrm{CO}, 60 \% \mathrm{H}_{2}, 10 \% \mathrm{~N}_{2}\right), 250{ }^{\circ} \mathrm{C}, 20$ bar for 96 hours. Various catalyst weight $(1,1.2,1.4,1.6$ gram) were applied in FTS. The desilicated HZSM-5 properties (BET analysis) were 6.1-29.9 nm mesoporous diameter, $0.3496 \mathrm{cc} / \mathrm{g}$ average mesoporous volume, $526.035 \mathrm{cc} / \mathrm{g}$ pore surface area, and the EDX analysis gave $22.1059 \mathrm{Si} / \mathrm{Al}$ ratio and $16.11 \%$ loading (by weight) on meso-HZSM-5. The reduced catalyst showed the XRD spectra of $\mathrm{Fe}\left(66^{\circ}\right)$, Fe-Co alloy $\left(44.50^{\circ}\right)$ and $\mathrm{Co}_{3} \mathrm{O}_{4}\left(36.80^{\circ}\right)$. The reaction using 1 gram of $10 \mathrm{Fe}-90 \mathrm{Co} / \mathrm{meso}-\mathrm{HZSM}-5$ catalyst produced the largest composition and conversion. The 1 gram catalyst gave the largest normal selectivity of gasoline (19.15\%) and kerosene (55.18 \%). While the largest normal diesel oil selectivity $(24.17 \%)$ was obtained from 1.4 gram of catalyst. The CO conversion per gram of catalyst showed similar value (CO conversion of 26-28\%) for all catalyst weight.
\end{abstract}

Keywords: biofuel, HZSM-5, desilication, mesopore, catalyst, iron, cobalt, weight, conversion, Fischer-Tropsch.

DOI: $10.21303 / 2461-4262.2021 .001657$

\section{Introduction}

Zeolites are used in the process of separation, adsorption, and catalytic (i. e. cracking and other hydrotreating process). Homogeneous micropores, high thermal stability, acidity, and unique ability to stabilize metallic species were several their unique properties [1]. The mesoporous structure provides greater space for metal catalysts to occupy more support pores. The mesopore can be obtained from micropore over desilication treatment. The alkali $(\mathrm{NaOH})$ solution was used as desilication agent. Nitric acid solution was used to transform the mesoporous HZSM-5 into 
amorphous structure, which could improve the adhesion of the metal catalyst on the mesoporous HZSM-5 support [2-5]. The KOH solution induced greater mesoporous volumes, but it damaged on zeolite crystal structure. The $\mathrm{NaOH}$ solutions were able to increased mesopore surface area and mesopore volume of $\mathrm{NaOH}$-desilicated HZSM-5. The Fe-Co alloys were observed with less oxide of iron $\left(\mathrm{Fe}_{2} \mathrm{O}_{3}\right)$ as well cobalt $\left(\mathrm{Co}_{3} \mathrm{O}_{4}\right)$ in the produced catalysts [6].

The Fischer-Tropsch synthesis (FTS) is an exothermic and irreversible polymerization reaction that converts a mixture of hydrogen $\left(\mathrm{H}_{2}\right)$ and carbon monoxide $(\mathrm{CO})$ into linear hydrocarbons as liquid fuel. FTS always produces various products such as olefins, paraffins and oxygenated compounds (alcohols, aldehydes, acids and ketones). Water was the main product of the FT reaction. Water Gas Shift (WGS) activity occured significantly in the use of Fe catalyst, but this reaction could be ignored in reactions using Co or Ru catalysts. Iron and cobalt as polymerization catalyst were used at FTS. The impregnated iron and cobalt on HZSM-5 could be used as bifunction catalyst which combined polymerizing synthesis gas and long chain hydrocarbon cracking for making biofuel [3, 7-10]. The FTS preferred to use cobalt because of some advantages, instead of iron catalyst. Iron catalyst was added in little amount to improve the cobalt catalyst performance (improve olefin selectivity, reduce methane selectivity, reduce temperature and pressure sensitivity to product distribution and reduce the catalyst price) [11, 12].

The combination of the Fischer-Tropsch (FT) reaction and cracking was conducted by combining Fe-Co alloy (Fischer-Tropsch reaction catalyst) and HZSM-5 zeolite (cracking catalyst). The merging of the FTS and cracking was able to produce biofuel product directly [7]. The Fe/HZSM-5 catalyst was able to produce $24.2 \%$ of $\mathrm{C}_{5-19}$ hydrocarbon as biofuel fraction [8]. The Co/HZSM-5 catalyst produced $48 \%$ of $\mathrm{C}_{5-11}$ [3]. The use of $\mathrm{Fe}$ and Co catalysts together (bimetallic) could increase catalytic activity compared to the use single metal catalyst (monometallic). The combination of $\mathrm{Fe}$ and $\mathrm{Co}$ catalysts (bimetal catalysts) with conventional $\mathrm{TiO}_{2}, \mathrm{Al}_{2} \mathrm{O}_{3}$ and $\mathrm{SiO}_{2}$ supports had been investigated. They could increase the biofuel reaction conversion and fraction compared to the use of Fe and Co catalysts separately [13-15]. The variables that influenced product distribution were temperature, feed gas composition, pressure, catalyst type and promoter. The synthesis gas composition influenced the product selectivity. The lower the CO partial pressure, the lower the surface coverage of $\mathrm{CH}_{2}$ radicals, the lower the chain growth chance and the higher the chance of $\mathrm{CH}_{2}$ radicals desorption. The higher the $\mathrm{H}_{2}$ partial pressure, increases the chance of radicals termination being paraffin. Increasing $\mathrm{H}_{2} / \mathrm{CO}$ ratio would increase the selectivity of short-chain and more saturated hydrocarbons [16-18].

The study emphasized the effect of $\mathrm{Fe}-\mathrm{Co} / \mathrm{mesoHZSM} 5$ catalyst weight on product composition and conversion. The data obtained from this study will be used to develop efficiency of the Fischer-Tropsch reaction condition.

\section{Methods}

Materials used in this experiment were zeolite ZSM-5 in ammonium form (CBV 8014, Amberlyst International), $\mathrm{Fe}\left(\mathrm{NO}_{3}\right)_{3} \cdot 9 \mathrm{H}_{2} \mathrm{O}$ (Merck), $\mathrm{Co}\left(\mathrm{NO}_{3}\right)_{2} \cdot 6 \mathrm{H}_{2} \mathrm{O}$ (Merck), $\mathrm{NaOH}$ p.a. (Merck), nitric ammonium p.a. (Merck), nitric acid (Merck), Hydrogen gas (PT. Samator Gas Industry, Surabaya, Indonesia), synthesis gas $\left(30 \% \mathrm{CO}, 60 \% \mathrm{H}_{2}, 10 \% \mathrm{~N}_{2}\right.$ ), glass beads $2 \mathrm{~mm}$ (Marienfeld), glass wool, aquadest. The equipment used were the tubular furnace, quartz furnace crucible, hotplate magnetic stirrer, vacuum filter, air compressor, hot air oven, syringe, digital scales and standard glassware for catalyst synthesis. The continuous fixed-bed Fischer-Tropsch reactor (Fig. 1), hot trap, cold trap, bubble soap meter, vacutainer (vacuum bottle/container) were used for FTS.

The 10Fe-90Co/meso-HZSM-5 catalyst was prepared from ammonium salt of ZSM-5 over calcination, desilication, dispersion, acid treatment [6]. The solution of $\mathrm{Co}\left(\mathrm{NO}_{3}\right)_{2} \cdot 6 \mathrm{H}_{2} \mathrm{O}$ and $\mathrm{Fe}\left(\mathrm{NO}_{3}\right)_{3} \cdot 9 \mathrm{H}_{2} \mathrm{O}$ were used as precursor for incipient wetness impregnation (IWI) process on amorphous meso-HZSM-5. Loading metal catalyst was $10 \%$. The catalyst consisted of $10 \%$ Fe (by weight) and $90 \%$ Co (by weight). The impregnated HZSM-5 was kept in desiccator at room temperature for 24 hours, dried in oven at $120^{\circ} \mathrm{C}$ for 12 hours and then calcined at $550{ }^{\circ} \mathrm{C}$ for 2 hours. 


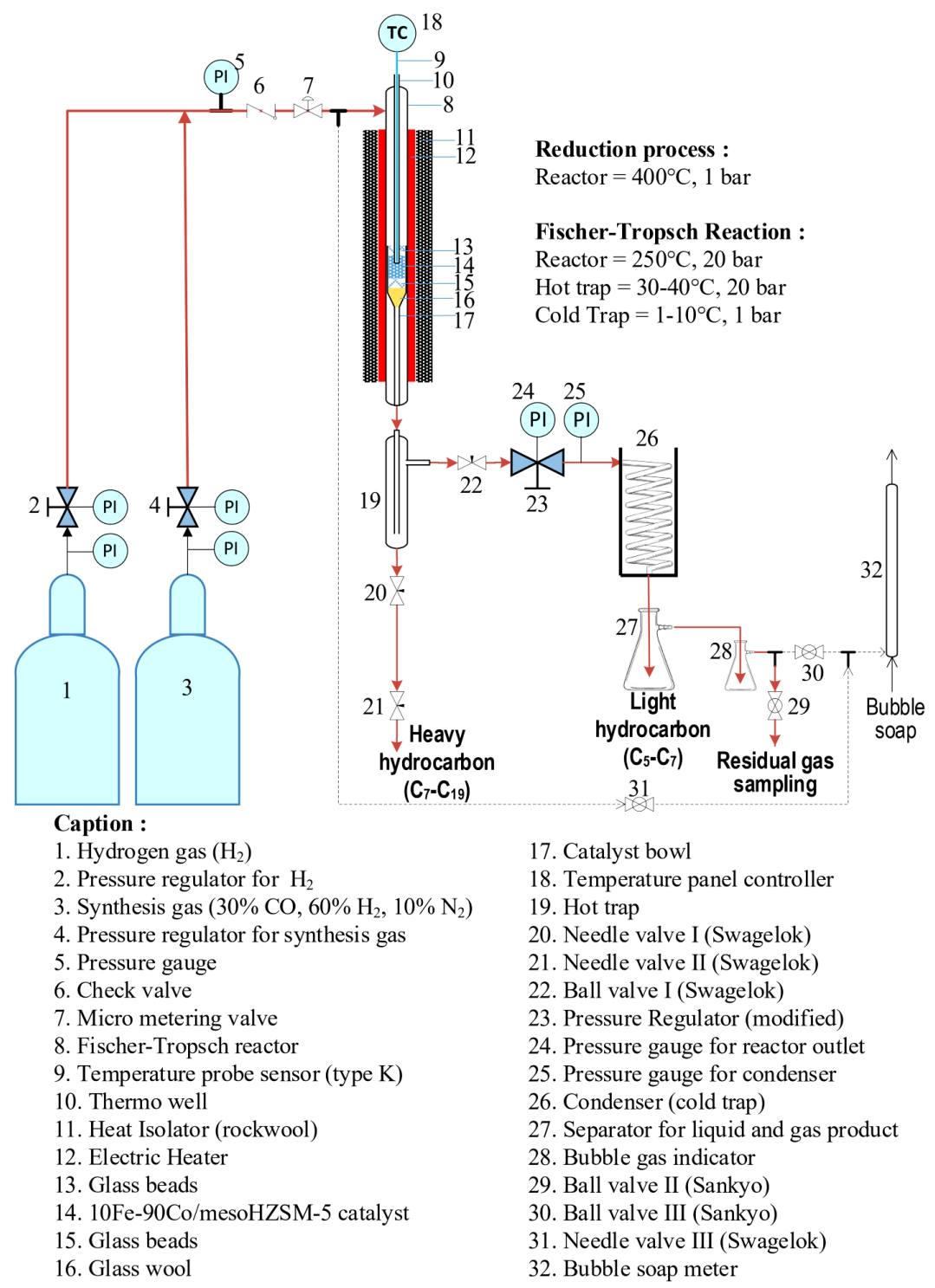

Fig. 1. The reactor unit of continuous Fischer-Tropsch synthesis for $10 \mathrm{Fe}-90 \mathrm{Co} / \mathrm{meso}-\mathrm{HZSM}-5$ catalyst using synthesis gas $\left(30 \% \mathrm{CO}, 60 \% \mathrm{H}_{2}, 10 \% \mathrm{~N}_{2}\right), 25 \mathrm{~mL} / \mathrm{min}, 250{ }^{\circ} \mathrm{C}, 20 \mathrm{bar}$, 96 hours on various catalyst weight variation $(1 ; 1.2 ; 1.4 ; 1.6$ gram)

The catalyst performance was observed in a continuous fixed bed reactor (Fig. 1) using 10Fe-90Co/meso-HZSM-5 catalyst, $25 \mathrm{~mL} / \mathrm{min}$ synthesis gas $\left(30 \% \mathrm{CO}, 60 \% \mathrm{H}_{2}, 10 \% \mathrm{~N}_{2}\right)$ at $250{ }^{\circ} \mathrm{C}, 20$ bar. Various catalyst weight $(1 ; 1.2 ; 1.4 ; 1.6$ gram $)$ were used in the Fischer-Tropsch reaction. The catalyst was mixed with glass beads as much as 6 times of the catalyst weight. The mixture of catalyst and glass beads was inserted into the catalyst bowl which was held with glass wool at the bottom and top of the catalyst to prevent the spilling out of the catalyst during process [19-22]. All catalysts were reduced in situ in the reactor with $\mathrm{H}_{2}$ gas flowing at $25 \mathrm{~mL} / \mathrm{min}, 1 \mathrm{bar}, 400{ }^{\circ} \mathrm{C}$ for 10 hours. At the end of the reduction procedure, the reactor was cooled to $250{ }^{\circ} \mathrm{C}$ and the hydrogen gas flow was stopped, then it was replaced by the synthesis gas flow. The modified pressure regulator was installed after the reactor to maintain 20 bar pressure. The flow rate was calibrated using bubble soap meter at $25 \mathrm{~mL} / \mathrm{min}$ at the operating pressure and temperature. Some hydrocarbon fractions condensed through hot trap at $30-40{ }^{\circ} \mathrm{C}$ and 20 bar. The low boiling point hydrocarbon fraction would be condensed in a cold trap $\left(1-10^{\circ} \mathrm{C}, 1\right.$ bar). The reaction was carried out for 96 hours with gas sampling every 24 hours and liquid sampling at the end of the whole reaction. Gas samples were taken using a $10 \mathrm{~mL}$ syringe and injected into $10 \mathrm{~mL}$ vacuum bottle (vacutainer). 


\section{Result and discussion}

\section{1. Characterization of Catalyst Fe-Co/meso-HZSM-5}

Ammonium ZSM-5 (Si/Al=40) was converted to microporous HZSM-5 through calcination process in the tube furnace reactor. The formation of mesoporous structures was obtained through the desilication process in which silicon was partly-removed from zeolite framework using $\mathrm{NaOH}$ as desilication agent. The desilicated HZSM-5 properties obtained from BET analysis were $6.1-29.9 \mathrm{~nm}$ mesoporous diameter, $0.3496 \mathrm{cc} / \mathrm{g}$ average mesoporous volume, $526.035 \mathrm{cc} / \mathrm{g}$ pore surface area, and from EDX analysis gave $22.1059 \mathrm{Si} / \mathrm{Al}$ ratio.

The Fe and Co catalysts loading was $16.11 \%$ weight on mesoporous HZSM-5. The loading of catalyst was calculated from EDX analyzing. The impregnated mesoporous HZSM-5 was reduced to obtain metal catalyst on the active surface. The XRD analysis was used to observe the reduction results. The diffraction angle position of the metal peaks referred to the spectral Tavasoli's database [23]. The spectra of $\mathrm{Fe}\left(66^{\circ}\right)$, Fe-Co alloy $\left(44.50^{\circ}\right)$ and $\mathrm{Co}_{3} \mathrm{O}_{4}\left(36.80^{\circ}\right)$ were shown in Fig. 2.

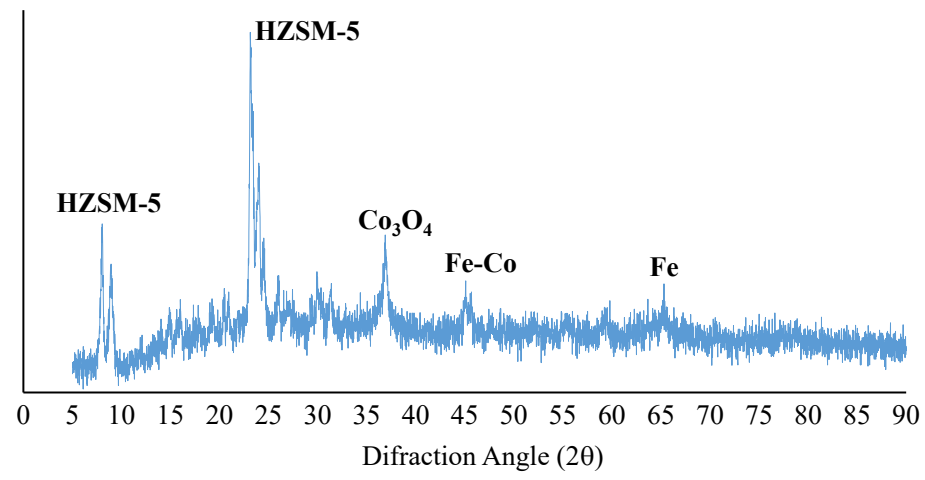

Fig. 2. The XRD Spectra for Fe-Co/HZSM-5 catalyst consisted of $10 \% \mathrm{Fe}$ and $90 \% \mathrm{Co}$ after reduction (with $\mathrm{H}_{2}$ gas flowing at $25 \mathrm{~mL} / \mathrm{min}, 1$ bar, $400{ }^{\circ} \mathrm{C}$ for 10 hours)

\section{2. Effect of catalyst weight to product composition}

The FTS reaction produced two layers liquid product, each of which has a pungent odor. The two layer liquid products were taken from hot trap chamber $\left(30-40^{\circ} \mathrm{C}\right)$. Both of layers had similar viscosity. The upper layer ass clear yellow, while the lower layer was colorless. From GCMS analysis, the upper layer contained alkanes (paraffin) and less alkene (olefin). Carboxylic acids, alcohols, esters and aromatic compounds were found in the lower layer products. The increasing catalyst weight gave the higher alkane selectivity. One gram of catalyst obtained $85.04 \%$ alkanes and $7.56 \%$ alkenes. The alkane composition rose to $96.33 \%$ on 1.2 grams of catalyst and increased again to $99.96 \%$ on 1.4 and 1.6 grams of catalyst. Straight chain hydrocarbon selectivity was quite large $(57-72 \%)$. The 1.6 gram catalyst gave the greatest selectivity $(72.03 \%)$ when compared to $57.14 \%$ on 1 gram catalyst. The more catalysts used, the greater active surface involved in the reaction so that the catalyst's performance was better. The reactants contained double $\mathrm{H}_{2}$ than $\mathrm{CO}\left(\mathrm{H}_{2} / \mathrm{CO}\right.$ ratio $\left.=2\right)$. The greater active surface area increased the concentration of hydrogen free radicals, so the reaction mechanism lead to the formation of paraffins and carboxylic acids.

The combination of polymerization using metal catalyst (Fe-Co) and cracking (mesoHZSM-5) in the FTS intended to produce saturated $\mathrm{C}_{5}-\mathrm{C}_{19}$ hydrocarbons (gasoline, kerosene and diesel oil). The product distribution based on the hydrocarbon chain length in the both layers could be seen in Fig. 3, 4. The upper layer was dominated by alkane hydrocarbons with $\mathrm{C}_{7}-\mathrm{C}_{25}$ hydrocarbon chain length (Fig. 3). The use of 1 and 1.2 gram catalysts produced $\mathrm{C}_{7}-\mathrm{C}_{19}$ hydrocarbon while the more catalyst weight produced less $\mathrm{C}_{20}-\mathrm{C}_{25}$ hydrocarbon (below $1.7 \%$ ). The 1 and 1.2 gram catalyst might form $\mathrm{C}_{20}-\mathrm{C}_{25}$ in such a small amount, so that GCMS could not detect this traces. Increasing catalyst weight would rise the reaction chance on the catalyst active surface so that the more product was obtained (higher conversion) and the presence of $\mathrm{C}_{20}-\mathrm{C}_{25}$ hydrocarbon could be measured using GCMS. The FT reaction using 10Fe-90Co/meso-HZSM-5 catalyst at $250{ }^{\circ} \mathrm{C}$ and 1 bar produced gasoline, kerosene and diesel oil. Kerosene was the largest product (55.18-61.68 \%), 
was obtained from the catalyst weight of 1-1.6 gram. The largest gasoline fraction (19.15\%) was obtained from 1 gram of catalyst and decreased with increasing catalyst weight. The diesel oil fraction increased with the catalyst weight. The largest solar fraction (19.34 \%) was obtained from 1.6 gram of catalyst. The greater the catalyst weight, the greater the diesel fuel produced and the smaller the gasoline produced.

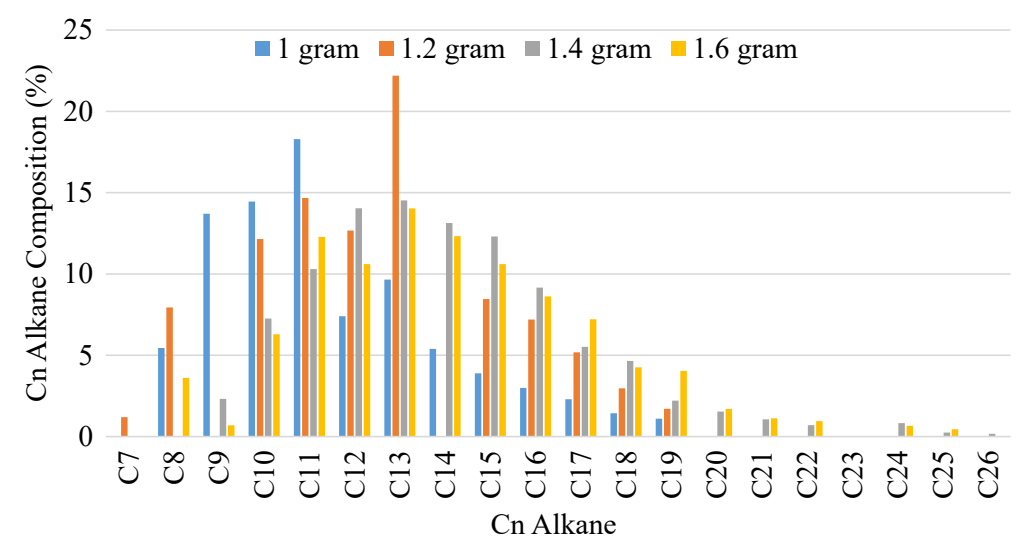

Fig. 3. Distribution of upper layer liquid products from Fischer-Tropsch reaction with catalyst 10Fe-90Co/meso-HZSM-5, loading $10 \%$, synthesis gas $\left(30 \% \mathrm{CO}, 60 \% \mathrm{H}_{2}, 10 \% \mathrm{~N}_{2}\right)$, $25 \mathrm{~mL} / \mathrm{min}, 250^{\circ} \mathrm{C}, 20 \mathrm{bar}, 96$ hours at various catalyst weight variation $(1 ; 1.2 ; 1.4 ; 1.6$ gram $)$

The lower layer showed the FTS side reaction, that produced alcohol, carboxylic acid, ester, aromatic and cycloalkane compounds (Fig. 4). The carboxylic acid was formed at any weight variation. The alcohol was formed in large amount at 1.2 and 1.4 gram catalyst. This condition could be used to alternative alcohol production from synthesis gas with this catalyst.

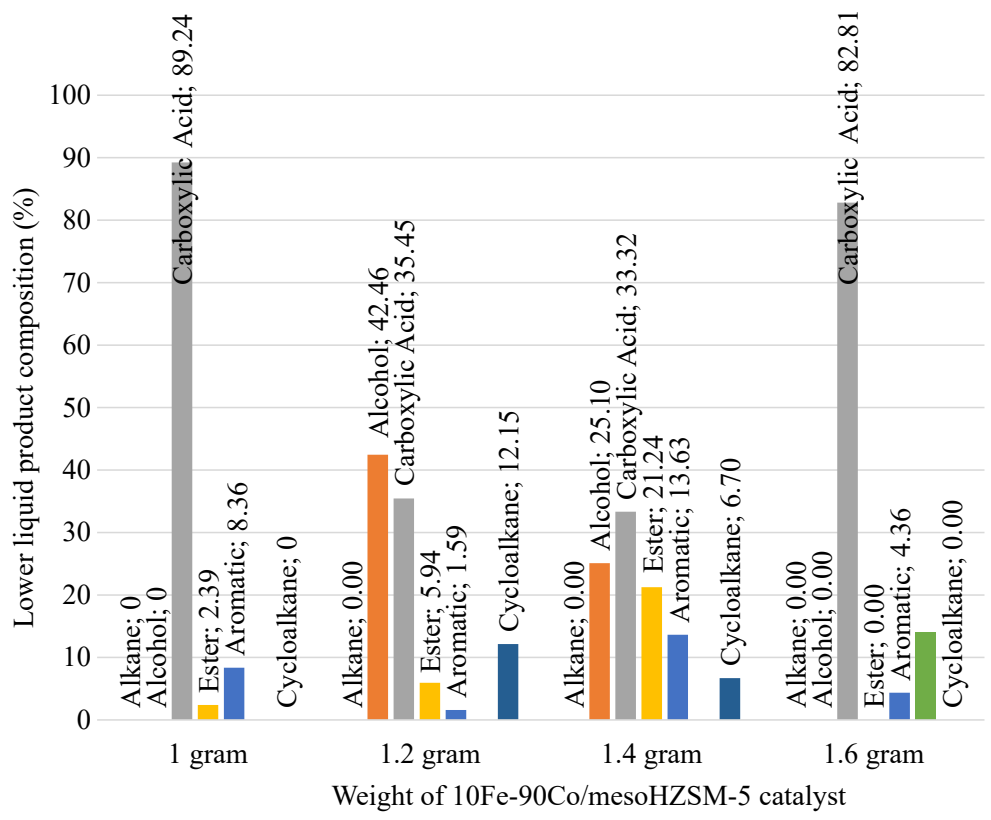

Fig. 4. Distribution of lower layer liquid products from Fischer-Tropsch reaction with catalyst 10Fe-90Co/meso-HZSM-5, loading $10 \%$, synthesis gas ( $30 \% \mathrm{CO}, 60 \% \mathrm{H}_{2}, 10 \% \mathrm{~N}_{2}$ ), $25 \mathrm{~mL} / \mathrm{min}, 250^{\circ} \mathrm{C}, 20$ bar, 96 hours at various catalyst weight variation $(1 ; 1.2 ; 1.4 ; 1.6$ gram $)$

The more 10Fe-90Co/meso-HZSM-5 catalyst, which used in the FT reaction, would have the greater active surface area. They might increase the reaction chances that increased $\mathrm{CO}$ con- 
version (Fig. 5). The larger active surfaces would increase $\mathrm{CO}$ dissociation which initiated the polymerization process. The $\mathrm{CO}$ conversion on 1 gram of catalyst was $27.33 \%$ which increased to $42.46 \%$ on the use of 1.6 grams of catalyst.

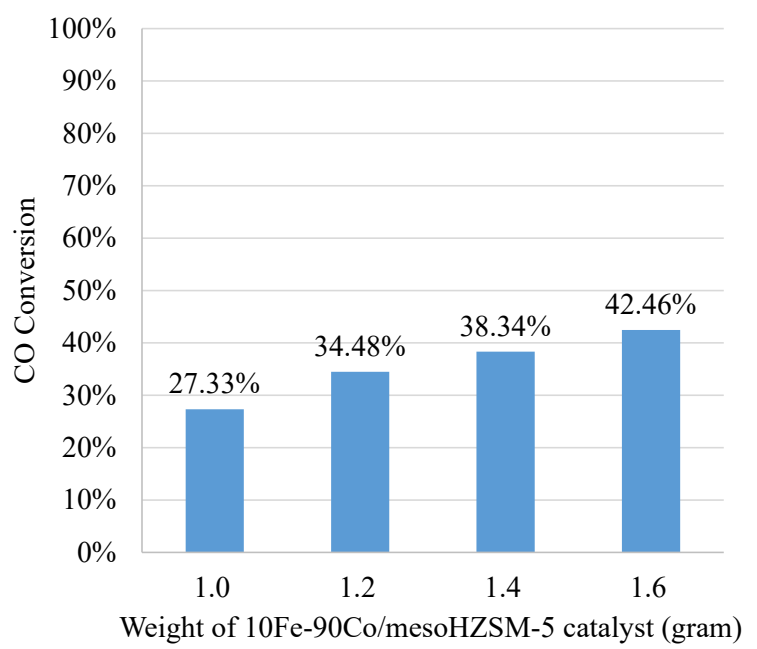

Fig. 5. The $\mathrm{CO}$ conversion from the Fischer-Tropsch reaction with catalyst

10Fe-90Co/meso-HZSM-5, loading $10 \%$, synthesis gas $\left(30 \% \mathrm{CO}, 60 \% \mathrm{H}_{2}, 10 \% \mathrm{~N}_{2}\right)$, $25 \mathrm{~mL} / \mathrm{min}, 250{ }^{\circ} \mathrm{C}, 20 \mathrm{bar}, 96$ hours on various catalyst weight variation $(1 ; 1.2 ; 1.4 ; 1.6$ gram)

The residual gas consisted of $\mathrm{CO}, \mathrm{H}_{2}, \mathrm{CO}_{2}$ and $\mathrm{CH}_{4}$ were measured by GC-TCD (Fig. 6). The decreasing $\mathrm{CO}$ fraction in the residual gas showed that $\mathrm{CO}$ consumption increased with more catalysts being used. The formation of a relatively small $\mathrm{CO}_{2}$ indicated that the WGS reaction was not dominant in the condition and catalyst used. The greater Co catalyst ( $90 \%$ ) in the bimetal $\mathrm{Fe}-\mathrm{Co}$ did not push WGS reaction. But with increasing catalyst weight, the Fe weight was also larger, so that more $\mathrm{CO}_{2}$ gas formation (1-2\%) was obtained in the use of catalysts 1.2-1.6 gram. However, the larger $\mathrm{Co}$ in the Fe-Co would drive the methane formation. The analysis showed that methane was formed in all catalyst weight insignificantly. In the 1 gram of catalyst, only $1 \%$ methane was formed, while the use of more catalysts produced 5-6\% methane. The bimetal combination on supported mesoporous HZSM-5 reduced methane formation significantly compared to previous studies $[3,15,24]$, which produced $7.9-21 \%$ methane.

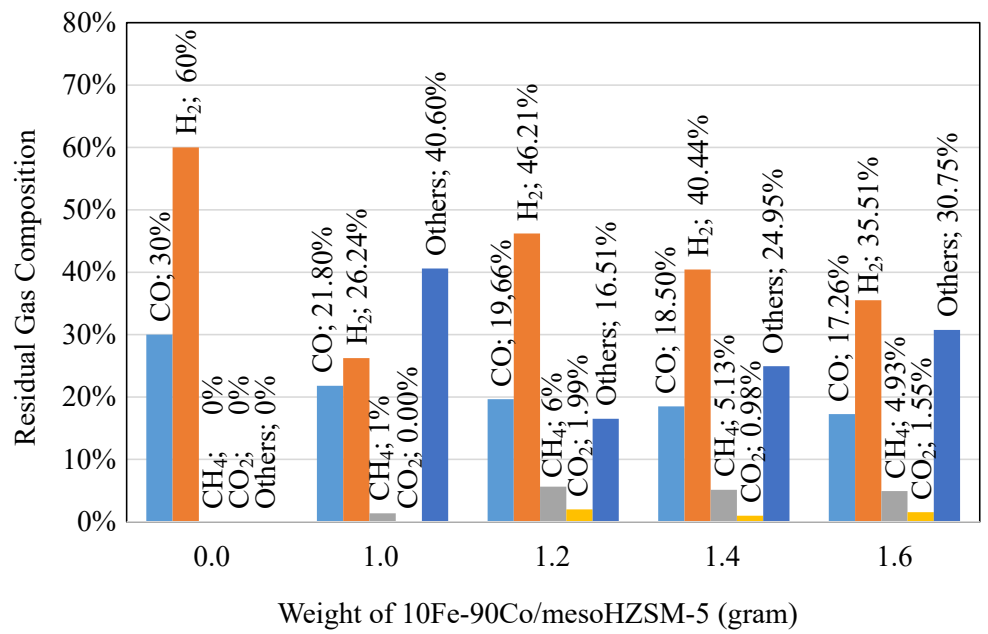

Fig. 6. The residual gas composition from the Fischer-Tropsch reaction with catalyst 10Fe-90Co/meso-HZSM-5, loading $10 \%$, synthesis gas $\left(30 \% \mathrm{CO}, 60 \% \mathrm{H}_{2}, 10 \% \mathrm{~N}_{2}\right)$, $25 \mathrm{~mL} / \mathrm{min}, 250{ }^{\circ} \mathrm{C}, 20$ bar, 96 hours on various catalyst weight variations $(1 ; 1.2 ; 1.4 ; 1.6$ gram $)$ 


\section{3. Normalization of Selectivity and Conversion}

Normalization of liquid products selectivity and reaction conversion to catalyst weight was conducted to determine the efficiency and effectiveness of the catalysts use. The product selectivity and conversion were normalized by the catalyst weight that was varied in this study. This normalization data could be used to take better decision in the catalyst efficiency and effectiveness before commercializing.

Normalization of biofuel selectivity (gasoline, kerosene and diesel) to the $10 \mathrm{Fe}-90 \mathrm{Co} / \mathrm{me}-$ so-HZSM- 5 catalyst weight in the FT reaction of $250{ }^{\circ} \mathrm{C}, 20$ bar using synthesis gas $(30 \% \mathrm{CO}$, $60 \% \mathrm{H}_{2}, 10 \% \mathrm{~N}_{2}$ ) for 96 hours was shown in Fig. 7. The 1 gram catalyst weight gave the largest normal selectivity to gasoline (19.15\%) and kerosene (55.18 \%). While the largest normal diesel oil selectivity $(24.17 \%)$ was obtained from the use of 1.4 gram of catalyst weight.

Normalization of $\mathrm{CO}$ reaction conversion to the $10 \mathrm{Fe}-90 \mathrm{Co} / \mathrm{meso}-\mathrm{HZSM}-5$ catalyst weight in the $250{ }^{\circ} \mathrm{C}, 20$ bar FT reaction using synthesis gas $\left(30 \% \mathrm{CO}, 60 \% \mathrm{H}_{2}, 10 \% \mathrm{~N}_{2}\right)$ for 96 hours was shown in Fig. 8. The resulting normal conversion showed similar value for all catalyst in the range of $0.26-0.28$. All catalyst weight variation showed similar normal conversion over 96 hours, so the use of 1 gram of catalyst was more economically beneficial. These results were in line with the normal selectivity of gasoline and kerosene products that reached the highest value on the use of 1 gram of catalyst.

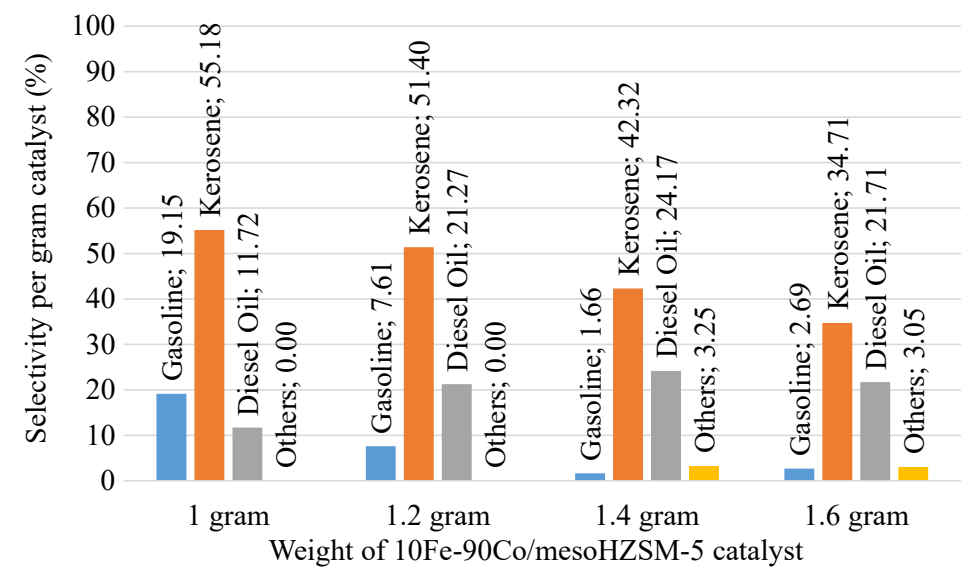

Fig. 7. Normalization of biofuel selectivity (gasoline, kerosene and diesel) to the $10 \mathrm{Fe}-90 \mathrm{Co} /$ meso-HZSM- 5 catalyst weight in the $250^{\circ} \mathrm{C}, 20 \mathrm{bar}$ Fischer-Tropsch reaction of using synthesis gas $\left(30 \% \mathrm{CO}, 60 \% \mathrm{H}_{2}, 10 \% \mathrm{~N}_{2}\right)$ for 96 hours

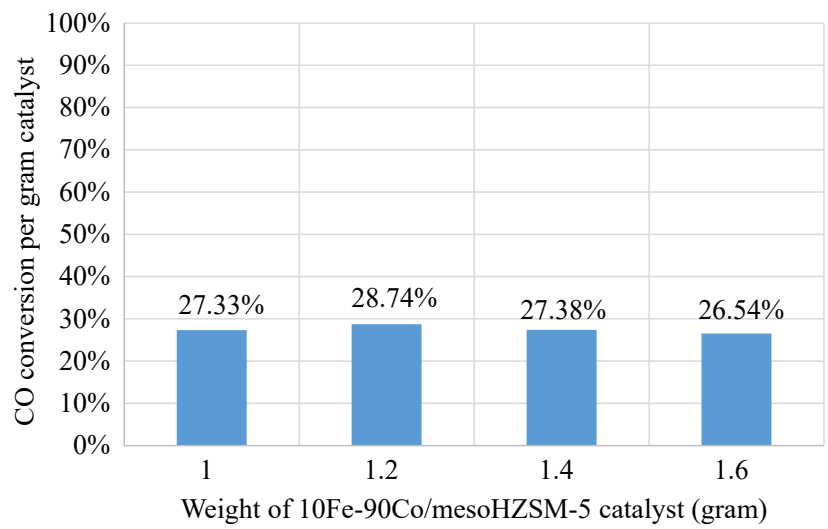

Fig. 8. Normalization of CO conversion to the $10 \mathrm{Fe}-90 \mathrm{Co} / \mathrm{meso}-\mathrm{HZSM}-5$ catalyst weight variation in the $250^{\circ} \mathrm{C}, 20$ bar Fischer-Tropsch reaction using synthesis gas $(30 \% \mathrm{CO}$, $60 \% \mathrm{H}_{2}, 10 \% \mathrm{~N}_{2}$ ) for 96 hours

This research has several limitations. A very expensive synthesis gas as raw material make biofuel price can't compete with the fossil fuel. The separated hydrogen, carbonmonoxide and 
nitrogen with each rate controller could be used to reduce raw material price. Coal or biomass that have the lowest price raw material, could be interesting for the next research. The catalyst development need further research to improve the reaction conversion in simple reactor and mild operation condition (temperature, pressure and time). Continuously data will give better reaction kinetics analysis for gaining best condition. The residual gas analysis as conversion indicator need to be measured continuously with integrated GC-TCD, instead of separately one. Gas sensor with Arduino program could be use as alternative to collect large data every seconds or minutes. The carbon monoxide sensor (MQ-7), carbon dioxide sensor (MG-811) and methane sensor (MQ-4) should be developed and integrated with Fischer-Tropsch reactor system.

\section{Conclusion}

The desilicated HZSM-5 properties (BET analysis) were 6.1-29.9 nm mesoporous diameter, $0.3496 \mathrm{cc} / \mathrm{g}$ average mesoporous volume, $526.035 \mathrm{cc} / \mathrm{g}$ pore surface area, and the EDX analysis gave $22.1059 \mathrm{Si} / \mathrm{Al}$ ratio and $16.11 \%$ loading (by weight) on meso-HZSM-5. The reduced catalyst showed the XRD spectra of $\mathrm{Fe}\left(66^{\circ}\right)$, Fe-Co alloy $\left(44.50^{\circ}\right)$ and $\mathrm{Co}_{3} \mathrm{O}_{4}\left(36.80^{\circ}\right)$.

The Fischer-Tropsch reaction using 1 gram of $10 \mathrm{Fe}-90 \mathrm{Co} / \mathrm{meso}-\mathrm{HZSM}-5$ catalyst and synthesis gas $\left(30 \% \mathrm{CO}, 60 \% \mathrm{H}_{2}, 10 \% \mathrm{~N}_{2}\right)$ at $250{ }^{\circ} \mathrm{C}, 20$ bar, 96 hours in the continuous fixed-bed reactor, showed the largest composition and conversion. The combination of polymerization using metal catalyst ( $\mathrm{Fe}-\mathrm{Co}$ ) and cracking (meso-HZSM-5) was intended to produce saturated $\mathrm{C}_{5}-\mathrm{C}_{25}$ hydrocarbons (gasoline, kerosene and diesel oil). The 1 gram catalyst weight gave the largest normal selectivity to gasoline (19.15\%) and kerosene (55.18 \%). While the largest normal diesel oil selectivity $(24.17 \%)$ was obtained from 1.4 gram of catalyst. The CO conversion per gram of catalyst showed similar value (26-28\%) for all catalyst weight.

\section{References}

[1] Wang, Y., Wang, R., Xu, D., Sun, C., Ni, L., Fu, W. et. al. (2016). Synthesis and properties of MFI zeolites with microporous, mesoporous and macroporous hierarchical structures by a gel-casting technique. New Journal of Chemistry, 40 (5), 4398-4405. doi: https://doi.org/10.1039/c5nj03387j

[2] Sun, X., Sartipi, S., Kapteijn, F., Gascon, J. (2016). Effect of pretreatment atmosphere on the activity and selectivity of Co/mesoHZSM-5 for Fischer-Tropsch synthesis. New Journal of Chemistry, 40 (5), 4167-4177. doi: https://doi.org/10.1039/c5nj02462e

[3] Valero-Romero, M. J., Sartipi, S., Sun, X., Rodríguez-Mirasol, J., Cordero, T., Kapteijn, F., Gascon, J. (2016). Carbon/H-ZSM-5 composites as supports for bi-functional Fischer-Tropsch synthesis catalysts. Catalysis Science \& Technology, 6 (8), 2633-2646. doi: https://doi.org/10.1039/c5cy01942g

[4] Jimmy, Ihsanti, D. H., Roesyadi, A., Suprapto, Kurniawansyah, F. (2019). Synthesis and Characterization of Fe-Co/mesoHZSM-5: Effect of Impregnated Ratio of Iron and Cobalt. IOP Conference Series: Materials Science and Engineering, 546, 072003. doi: https://doi.org/10.1088/1757-899x/546/7/072003

[5] Ihsanti, D. H., Jimmy, Kurniawansyah, F., Suprapto, Roesyadi, A. (2019). Performance of Bimetallic Fe and Co Catalyst Supported on HZSM-5 for Fischer-Tropsch Synthesis. IOP Conference Series: Materials Science and Engineering, 546, 042012. doi: https://doi.org/10.1088/1757-899x/546/4/042012

[6] Jimmy, Roesyadi, A., Suprapto, Kurniawansyah, F. (2020). Synthesis and characterization of Fe-Co/mesoHZSM-5: Effect of desilication agent and iron-cobalt composition. Korean Chemical Engineering Research, 58 (1), 163-169. doi: https://doi.org/ 10.9713/kcer.2020.58.1.163

[7] Sineva, L. V., Asalieva, E. Y., Mordkovich, V. Z. (2015). The role of zeolite in the Fischer-Tropsch synthesis over cobalt-zeolite catalysts. Russian Chemical Reviews, 84 (11), 1176-1189. doi: https://doi.org/10.1070/rcr4464

[8] Pour, A. N., Zare, M., Kamali Shahri, S. M., Zamani, Y., Alaei, M. R. (2009). Catalytic behaviors of bifunctional Fe-HZSM-5 catalyst in Fischer-Tropsch synthesis. Journal of Natural Gas Science and Engineering, 1 (6), 183-189. doi: https://doi.org/ 10.1016/j.jngse.2009.11.003

[9] Sartipi, S., Parashar, K., Valero-Romero, M. J., Santos, V. P., van der Linden, B., Makkee, M. et. al. (2013). Hierarchical H-ZSM-5-supported cobalt for the direct synthesis of gasoline-range hydrocarbons from syngas: Advantages, limitations, and mechanistic insight. Journal of Catalysis, 305, 179-190. doi: https://doi.org/10.1016/j.jcat.2013.05.012

[10] Kim, C.-U., Kim, Y.-S., Chae, H.-J., Jeong, K.-E., Jeong, S.-Y., Jun, K.-W., Lee, K.-Y. (2010). Effect of cobalt catalyst type and reaction medium on Fischer-Tropsch synthesis. Korean Journal of Chemical Engineering, 27 (3), 777-784. doi: https://doi.org/ $10.1007 / \mathrm{s} 11814-010-0135-5$ 
[11] Davis, B. H. (2007). Fischer-Tropsch Synthesis: Comparison of Performances of Iron and Cobalt Catalysts. Industrial \& Engineering Chemistry Research, 46 (26), 8938-8945. doi: https://doi.org/10.1021/ie0712434

[12] Min, S. K., No, S.-R., You, S.-S. (2017). Effect of composition of $\gamma-\mathrm{Al}_{2} \mathrm{O}_{3} / \mathrm{SiO}_{2}$ mixed support on Fischer-Tropsch synthesis with iron catalyst. Korean Chemical Engineering Research, 55 (3), 436-442. doi: https://doi.org/10.9713/kcer.2017.55.3.436

[13] Mukenz, T. M. (2010). Fischer-Tropsch Reaction: Towards understanding the mixed iron-cobalt catalyst systems. Johannesburg.

[14] Ali, S., Mohd Zabidi, N. A., Subbarao, D. (2011). Correlation between Fischer-Tropsch catalytic activity and composition of catalysts. Chemistry Central Journal, 5 (1). doi: https://doi.org/10.1186/1752-153x-5-68

[15] Mansouri, M., Atashi, H. (2016). Fischer-tropsch synthesis over potassium-promoted $\mathrm{Co}-\mathrm{Fe} / \mathrm{SiO}_{2}$ catalyst. Indian Journal of Chemical Technology, 23 (2), 453-461.

[16] Maitlis, P. M., de Klerk, A. (Eds.) (2013). Greener Fischer-Tropsch Processes for Fuels and Feedstocks. Wiley-VCH Verlag GmbH \& Co. KGaA. doi: https://doi.org/10.1002/9783527656837

[17] Davis, B. H. (2001). Fischer-Tropsch synthesis: current mechanism and futuristic needs. Fuel Processing Technology, 71 (1-3), 157-166. doi: https://doi.org/10.1016/s0378-3820(01)00144-8

[18] Filot, I. A. W., van Santen, R. A., Hensen, E. J. M. (2014). The Optimally Performing Fischer-Tropsch Catalyst. Angewandte Chemie International Edition, 53 (47), 12746-12750. doi: https://doi.org/10.1002/anie.201406521

[19] Al Fatony, Z., Febriani, Y., Makertihartha, I., Gunawan, M. L., Subagjo. (2019). Acidity effects of K promoted Co-based catalyst with $\mathrm{NH}_{4} \mathrm{OH}$ addition of the impregnation solution for Fischer-Tropsch synthesis. MATEC Web of Conferences, 268, 07001. doi: https://doi.org/10.1051/matecconf/201926807001

[20] AlFatony, Z., Resha, A. H., Persada, G. P. et. al. (2018). Effects of Cu on the modified Co-based catalyst activity for fischer-tropsch synthesis. ASEAN J. Chem. Eng., 18 (1), 60-70. Available at: https://jurnal.ugm.ac.id/AJChE/article/view/49548/25545

[21] Lippens, B. (1965). Studies on pore systems in catalysts V. The t method. Journal of Catalysis, 4 (3), 319-323. doi: https://doi.org/ 10.1016/0021-9517(65)90307-6

[22] Barrett, E. P., Joyner, L. G., Halenda, P. P. (1951). The Determination of Pore Volume and Area Distributions in Porous Substances. I. Computations from Nitrogen Isotherms. Journal of the American Chemical Society, 73 (1), 373-380. doi: https://doi.org/ $10.1021 / \mathrm{ja} 01145 \mathrm{a} 126$

[23] Tavasoli, A., Trépanier, M., Malek Abbaslou, R. M., Dalai, A. K., Abatzoglou, N. (2009). Fischer-Tropsch synthesis on mono- and bimetallic Co and Fe catalysts supported on carbon nanotubes. Fuel Processing Technology, 90 (12), $1486-1494$. doi: https://doi.org/10.1016/j.fuproc.2009.07.007

[24] Kim, J.-C., Lee, S., Cho, K., Na, K., Lee, C., Ryoo, R. (2014). Mesoporous MFI Zeolite Nanosponge Supporting Cobalt Nanoparticles as a Fischer-Tropsch Catalyst with High Yield of Branched Hydrocarbons in the Gasoline Range. ACS Catalysis, 4 (11), 3919-3927. doi: https://doi.org/10.1021/cs500784v

How to cite: Jimmy, J., Roesyadi, A., Suprapto, S., Kurniawansyah, F. (2021). Biofuel production over Fischer-Tropsch synthesis: effect of Fe-Co/meso-HZSM-5 catalyst weight on product composition and process conversion. EUREKA: Physics and Engineering, 6, 19-27. doi: https://doi.org/10.21303/2461-4262.2021.001657 